\title{
Epigenetic upregulation by valproic acid of transferrin receptor 1 , and not glucose transporter 1 or CD98hc, at the blood-brain barrier
}

\section{Steinunn Sara Helgudóttir}

Aalborg University

Kasper Bendix Johnsen

Lisa Juul Routhe

Aalborg University

Charlotte L.M. Rasmussen

Aalborg University

Azra Karamehmedovic

Aalborg University

Maj Schneider Thomsen

Aalborg University

Torben Moos ( $\nabla$ tmoos@hst.aau.dk)

Aalborg University

\section{Research Article}

Keywords: Blood-brain barrier, Transferrin receptor, Valproic acid

Posted Date: January 3rd, 2022

DOI: https://doi.org/10.21203/rs.3.rs-1220062/v1

License: (c) (1) This work is licensed under a Creative Commons Attribution 4.0 International License.

Read Full License 


\section{Abstract}

\section{Background}

The objectives of the present study were to investigate whether the expression of transferrin receptor 1 (TfR1), glucose transporter 1 (Glut1), or Cluster of Differentiation 98 Heavy Chain (CD98hc) is epigenetically regulated in brain capillary endothelial cells (BCECs) denoting the blood-brain barrier (BBB).

\section{Methods}

The expression of these targets was investigated both in vitro and in vivo following treatment with the histone deacetylase inhibitor (HDACi) valproic acid (VPA). Mice were injected intraperitoneally with VPA followed by analysis of isolated brain capillaries, and the capillary depleted brain samples. Brain tissue, isolated brain capillaries, and cultured primary endothelial cells were analyzed by RT-qPCR, immunolabeling and ELISA for expression of TfR1, Glut1 and CD98hc. We also studied the vascular targeting in VPA-treated mice injected with monoclonal anti-transferrin receptor (Ri7) conjugated with 1.4 nm gold nanoparticles.

\section{Results}

Validating the effects of VPA on gene transcription in BCECs, transcriptomic analysis identified 24,371 expressed genes, of which 305 were differentially expressed with 192 upregulated and 113 downregulated genes. In vitro using BCECs co-cultured with glial cells, the mRNA expression of Tfrc was significantly higher after VPA treatment for $6 \mathrm{~h}$ with its expression returning to baseline after $24 \mathrm{~h}$. Conversely, the mRNA expression of Glut1 and Cd98hc was unaffected by VPA treatment. In vivo, the TfR1 protein expression in brain capillaries increased significantly after treatment with both $100 \mathrm{mg} / \mathrm{kg}$ and $400 \mathrm{mg} / \mathrm{kg}$ VPA. Conversely, VPA treatment did not increase GLUT1 or CD98hc. Using ICP-MS-based quantification, the brain uptake of nanogold conjugated anti-TfR1 antibodies was non-significant in spite of increased expression of TfR1.

\section{Conclusions}

We report that VPA treatment upregulates TfR1 at the BBB both in vivo and in vitro in isolated primary endothelial cells. In contrast, VPA treatment does not influence the expression of GLUT1 and CD98hc. The increase in the overall TfR1 protein expression however does not increase transport of TfR-targeted monoclonal antibody and indicates that targeted delivery using the transferrin receptor should aim for increased mobilization of already available transferrin receptor molecules to improve trafficking through the BBB.

\section{Introduction}

While denoting the primary obstacle for delivering therapeutics to the brain ${ }^{1,2}$, the blood-brain barrier (BBB) is effective in maintaining a stable extracellular environment and prevents unwanted entry of 
toxins, pathogens, and other harmful molecules ${ }^{1,3,4}$. The BBB is formed by a monolayer of highly specialized brain capillary endothelial cells (BCECs) connected by their intermingling tight junctions, which limit non-specific, paracellular transport ${ }^{4-8}$. Crucial nutrients entering the brain undergo active transport via receptors and transporters expressed on the luminal surface of the BCECs; these receptors and transporters also have interest for delivering targeted therapeutics to the brain ${ }^{5,9}$.

Limited understanding of expressional patterns and functional regulation of these receptors and transporters remains a challenge for development of targeted drugs ${ }^{10}$. Drug delivery strategies often target endogenously expressed nutrient transporters delivering e.g. iron (transferrin receptor 1 (TfR1)), glucose (glucose transporter 1 (GLUT1)), or large amino acids (Cluster of Differentiation 98 Heavy Chain (CD98hc). Their availability is under influence of nutritional demand, age, inflammation, and other pathological processes ${ }^{11}$. The expression of nutrient transporters is probably also challenged by pharmacological treatment, and little is known about e.g the possible responses of BCECs to treatment with valproic acid (VPA) used for treatment in bipolar disorders or epilepsy. VPA induces epigenetic changes by inhibiting histone deacetylase, which further enables acetylation of histones and consequently gene transcription ${ }^{12}$. We have previously shown that the expression of ferroportin, another iron-transporting molecule (aka SLC40A1 or IREG1), is epigenetically upregulated in isolated rat BCECs in response to VPA treatment ${ }^{13}$.

The objective of the present work was to investigate whether VPA induces epigenetic changes at the level of the BBB to an extent that could modify the expression of important drug delivery targets, i.e. TfR1, GLUT1, and CD98hc for drug delivery to the brain ${ }^{14}$. We report that VPA treatment in mice upregulates TfR1 at the BBB in vivo when examining isolated brain capillaries and in vitro when studying isolated primary endothelial cells. In contrast, VPA treatment do not influence the expression of GLUT1 and CD98hc.

\section{Materials And Methods}

The following reagents were purchased from Sigma/Millicell Merck KGaA (Darmstadt, Germany, DE): Insulin transferrin sodium selenite (Cat. no. 11074547001), puromycin (Cat. no. P8833), collagen type IV (Cat. no. C5533), fibronectin (Cat. no. F1141), poly-L-lysine (Cat. no. P6282), hydrocortisone (HC) (Cat. no. H4001), dimethyl sulfoxide (DMSO) (Cat. no. D2650), 8-(4-chlorophenylthio)adenosine 3',5'-cyclic monophosphate sodium salt (CTP-cAMP) (Cat. no. C3912), 4-(3-butoxy-4-methoxybenzyl)imidazolidin-2one (RO) (Cat. no. B8279), paraformaldehyde (PFA) (Cat. no. 441244), triton x-100 (Cat. no. X100), 4',6diamidino-2-phenylindole dihydrochloride (DAPI), $\beta$-mercaptoethanol (Cat. no. M6250), cOmplete Mini, EDTA-free (Cat. no. 11836170001), valproic acid sodium salt (Cat. no. P4543), dextran (MW 60,000 Da), and percoll (Cat. no. P4937).

The following reagents were purchased from Thermo Scientific (Nærum, Denmark, DK): Fetal calf serum (FCS) (Cat. no. 10270), Dulbecco's Modified Eagle Medium consisting of nutrient mixture F-12 (DMEM/F12) (Cat. no. 31331), DMEM (low glucose) (Cat. no. 21885), DMEM (high glucose) (Cat. no. 31966), 
trypsin (Cat. no. 15090-46), phosphate-buffered saline (PBS) (Cat. no. SH3025802), rabbit anti-zonula occludens 1 (ZO-1) (Cat. no. 61-7300), Alexa Fluor 488-conjugated goat anti-rabbit IgG (Cat. no. A11034), Alexa Fluor 594-conjugated goat anti-rat IgG (Cat. no. A11007), RevertAid H Minus First Strand cDNA Synthesis Kit (Cat. no. K1652), DNase I enzyme (Cat. no. EN0521), TaqMan Multiplex MasterMix (Cat. no. 4484262), N-PER neuronal protein extraction reagent (Cat. no. 87792), BCA protein assay kit (Cat. no. 23225), TRIzol Plus RNA 41Purification Kit (Cat. no. 12183555). Taqman Fast Advanced MasterMix (Cat.No. 4444963). N-PER neuronal protein extraction reagent (Cat.no 87792). BCA protein essay kit (Cat.no. 23225). TRIzol Plus RNA Purification Kit (Cat.no 12183555). Taqman Probes for CD98hc (Cat.no. 4331182), Glut1 (Cat.no. 4331182), ICAM (Cat.no. 4331182), VCAM (Cat.no. 4331182), TfR1 (Cat.no. 4351370), Hprt1 (Cat.no. 4448490).

AllPrep DNA/RNA Mini Kit (Cat. no. 80204) was purchased from Qiagen. Greiner Bio-one Thincert cell culture inserts for 12 well plates with a transparent polyethylene terephthalate (PET) membrane and a pore diameter of $1 \mu \mathrm{m}$ (Cat. no. 665610) were purchased from In Vitro (Fredensborg, Denmark, DK). Basic fibroblast growth factor (bFGF) (Cat. no. 100-18B) was purchased from PeproTech Nordic (Stockholm, Sweden, SE). Gentamicin sulfate (Cat. no. 17-518Z) was purchased from Lonza Copenhagen (Vallensbaek Strand, Denmark, DK). Plasma-derived bovine serum (PDS) (Cat. no. 60-00-810) was purchased from First Link (Wolverhampton, United Kingdom, UK). Bovine serum albumin (BSA) (Cat. no. EQBAH62) was purchased from Europa Bioproducts (Cambridge, United Kingdom, UK). Fluorescence mounting medium (Cat. no. S3023) was purchased from DAKO (Glostrup, Denmark, DK). Rabbit antimouse Glut1 antibody (Cat. no. ab115730) was purchased from Abcam. Lycopersicon Esculentum (Tomato) Lectin DyLight® 594 (Cat. no. DL-1177-1) was purchased from Vector Laboratories. Mouse TfR1 ELISA kit (Cat. no. EKM2800) was purchased from BioSite. Isoflurane was purchased from Baxter A/S (Søborg, DK). Collagenase Type II was purchased from Life Technologies. Collagenase/dispase was purchased from Roche.

\section{Animals}

Animal experiments were approved by the Animal Experiments Inspectorate under the Danish Ministry of Environment and Food (license number: 2018-15-0201-01550) and performed under European Legislation of Animal Experimentation 2010/63/EU. A total of 48 C57BL/6JRj mice aged 5 weeks, $16-24 \mathrm{~g}$, were used for the study. In order to account for possible gender differences in response to VPA ${ }^{15,16}$, both males and female mice were included in the study. The mice were purchased from Janvier Labs (Le Genest-Saint-Isle, FR) and fed with a commercial diet (Altromin 1324, Brogaarden, Denmark) and water ad libitum. They were housed in cages of five with all experimental groups represented in each cage, and acclimatized to local environment (temperature $20-22{ }^{\circ} \mathrm{C}$, humidity $40-60 \%$, and light-dark cycle of 12 h) at the animal facility of Aalborg University for 14 days prior to experiments.

\section{VPA administration}


Mice were randomized into three groups based on body weight. VPA was diluted in sterile PBS and injected intraperitoneally (i.p.) in doses of $100 \mathrm{mg} / \mathrm{kg}$ or $400 \mathrm{mg} / \mathrm{kg}$, which are acceptable doses for mice ${ }^{17}$. Controls received injections of sterile PBS. Mice receiving a single VPA dose were euthanized $6 \mathrm{~h}$ or $24 \mathrm{~h}$ post-injection. Animals were weighed regularly and monitored for their well-being up until two hours post-injection. They were allowed to recover in a heated cage post-injection. VPA injected in dose of $100 \mathrm{mg} / \mathrm{kg}$ induced a phenotype where the mice became ataxic shortly after administration. In contrast, mice dosed with $400 \mathrm{mg} / \mathrm{kg}$ were heavily sedated, which lasted for up to $1 \mathrm{~h}$, after recovery they presented an ataxic phenotype, but capable of moving freely in their cage. The adverse effects disappeared within $24 \mathrm{~h}$ leading to full recovery of all mice.

\section{Tissue processing}

For histological purposes and for studies of isolated capillaries, mice were anaesthetized with hypnorm/dormicum solution and euthanized by transcardial perfusion of $20 \mathrm{~mL} 0.01 \mathrm{M} \mathrm{KPBS}(\mathrm{pH} 7.4)$. The brains were removed from the skull and dissected into left and right hemispheres and processed for immunohistochemistry and capillary depletion respectively. For immunohistochemical analyses, the left hemisphere from each mouse was fixed in $4 \%$ PFA at $4^{\circ} \mathrm{C}$ overnight, washed extensively in KPBS, immersed in $30 \%$ sucrose, and cryosectioned into $40 \mu \mathrm{m}$ free-floating coronal sections. A subset of mice $(\mathrm{n}=12)$ were intravenously injected with nanogold-conjugated anti-TfR1 antibodies (clone RI7217) $24 \mathrm{~h}$ after $100 \mathrm{mg} / \mathrm{kg}$ VPA treatment $(n=6)$ or injection of PBS $(n=6)$ (see below) and were anaesthetized and euthanized by transcardial perfusion with $20 \mathrm{~mL} 0.01 \mathrm{M} \mathrm{KPBS}(\mathrm{pH} 7.4)$ under isoflurane anesthesia; in these mice, brains and peripheral organs of interest were dissected, snap frozen in liquid nitrogen and kept at $-80^{\circ} \mathrm{C}$ until further analysis.

\section{Capillary depletion}

Brain capillary isolation was performed to separate the brain capillaries from the remaining brain tissue. From 12 mice per experimental group ( 6 males, 6 females), the brains were dissected, and the right cerebral hemisphere was sampled and transferred to a Dounce homogenizer. Ice-cold capillary depletion buffer ${ }^{18}$ was added, and the brains homogenized by six strokes, followed by mixing with ice-cold $30 \%$ dextran and further homogenization with six strokes. The homogenate was transferred into a $15 \mathrm{~mL}$ Falcon tube and centrifuged at $5,400 \mathrm{~g}$ for $40 \mathrm{~min}$ at $4^{\circ} \mathrm{C}$. The capillary and supernatant fractions were carefully separated and stored at $-80^{\circ} \mathrm{C}$ until further analyses.

\section{Labeling of anti-TrR1 antibodies with 1,4 nm gold nanoparticles}

To estimate the surface availability and transport capability of TfRs at the BBB, we used anti-TfR1 antibodies (clone RI7217, produced in-house using the hybridoma technique) ${ }^{19}$ labelled with $1.4 \mathrm{~nm}$ gold nanoparticles (Nanoprobes Inc., Yaphank, NY, US) for high sensitivity detection with inductively-coupled plasma-mass spectrometry. The stock buffer of the anti-TfR1 antibodies (PBS) was exchanged to $0.1 \mathrm{M}$ sodium borate buffer with $2 \mathrm{mM}$ EDTA $(\mathrm{pH} 8)$. The buffer-exchanged antibodies were then subjected to thiolation using Traut's reagent (Thermo Scientific, Hvidovre, DK) at a reagent-to-antibody ratio of 10 . The 
solution was allowed to incubate for one hour at room temperature under constant shaking at $500 \mathrm{rpm}$. The thiolated antibodies were then transferred to an Amicon Ultra spin filter (MW cut-off $30 \mathrm{kDa}$ ) (SigmaAldrich, Søborg, DK), topped with $5 \mathrm{~mL}$ sodium borate buffer, and centrifuged at $4000 \mathrm{~g}$ for $20 \mathrm{~min}$ at room temperature. The filter-through was discarded, and $5 \mathrm{~mL}$ PBS ( $\mathrm{pH}$ 7.4) was added to the thiolated antibodies. After volume reduction to $50 \mu \mathrm{L}$ by centrifugation, the thiolated antibodies were transferred to a Protein Lo-Bind Eppendorf tube and stored at $4 \mathrm{C}$ for no more than $30 \mathrm{~min}$. Conjugation of thiolated antibodies to the $1.4 \mathrm{~nm}$ gold nanoparticles was performed using Monomaleimide Nanogold Labeling Reagent (Nanoprobes Inc., Yaphank, NY, US) according to the manufacturer's instructions. In short, the lyophilized monomaleide nanoparticles were mixed in $1 \mathrm{~mL}$ deionized water and added to $2 \mathrm{mg}$ thiolated antibodies. The air phase was replaced with $\mathrm{N}_{2}$, and the solution was incubated at $4^{\circ} \mathrm{C}$ overnight. After incubation, the labeled antibodies were separated from unbound gold nanoparticles using gel filtration chromatography on a Superose 6 column (Sigma-Aldrich, Søborg, DK) and stored at $4^{\circ} \mathrm{C}$ until use.

\section{Quantification of tissue gold content}

The gold content in tissue samples was analyzed using inductively-coupled plasma-mass spectrometry. The samples were digested in aqua regia overnight at $65^{\circ} \mathrm{C}$ followed by dilution in deionized water containing $0.5 \mathrm{ppb}$ iridium (Fluka, Sigma-Aldrich, Brøndby, DK). Immediately prior to analysis, the samples were diluted in $2 \% \mathrm{HCl}$ containing $0.5 \mathrm{ppb}$ iridium, after which they were analyzed on an iCAP Q ICP-MS system (Thermo Scientific, Hvidovre, DK) fitted with an ASX-520 AutoSampler and a Neclar ThermoFlex 2500 chiller. Performance on the instrument was ensured by calibration using TUNE B iCAP Q element mixture (Thermo Scientific, Hvidovre, DK). A standard curve was generated by serial dilution of an analytical grade gold standard solution to obtain the gold concentration in each sample (Fluka, Sigma-Aldrich, Brøndby, DK). Measurement of the iridium concentration was used as an internal standard to ensure that all samples were analyzed in a similar manner.

\section{Primary cell cultures}

Mice were purchased from Janvier labs (Le Genest-Saint-Isle, FR). Primary brain capillary endothelial cells (BCECs) and pericytes were isolated from eight week old C57BL/6 mice as previously described ${ }^{20,21}$ The mice were anesthetized using isoflurane, and their heads submerged in $70 \%$ ethanol before decapitation. The meninges and the brain's cortical visible white matter were removed, and the remaining brain tissue immersed in cold DMEM-F12 medium. They were then digested in DMEM-F12 medium supplemented with collagenase type II and DNase I enzyme at $37^{\circ} \mathrm{C}$ for 75 minutes in an Incubated mini Shaker (VWR, Søborg, Denmark). Cells were then separated by mixing $20 \%$ bovine serum albumin (BSA) and centrifugation. The pellet containing the microvessel were further digested with collagenase/dispase and DNase I enzyme for 50 minutes at $37^{\circ} \mathrm{C}$, and separated on a $33 \%$ percoll gradient. Isolated BCECs were maintained in T75 flasks precoated with collagen IV and fibronectin in endothelial medium, which consisted of DMEM-F12 supplemented with $10 \%$ PDS, $0.1 \mathrm{mg} / \mathrm{mL}$ ITS, $10 \mu \mathrm{g} / \mathrm{mL}$ gentamicin sulfate, and freshly added $1 \mathrm{ng} / \mathrm{mL}$ bFGF. In order to remove pericyte contamination, the BCECs were cultured in media supplemented with $4 \mathrm{\mu g} / \mathrm{ml}$ puromycin for four days ${ }^{22,23}$. The cells were cultured in a $\mathrm{CO}_{2}$ 
incubator with $5 \% \mathrm{CO}_{2}$ and $95 \% \mathrm{O}_{2}$ at $37^{\circ} \mathrm{C}$. They were then passaged to 12-well hanging culture inserts precoated twice with $1 \mathrm{mg} / \mathrm{mL}$ collagen IV and $1 \mathrm{mg} / \mathrm{mL}$ fibronectin diluted in Milli-Q water at a density of $100.000 \mathrm{cells} / \mathrm{cm}^{2}$. Once the hanging insert culture contained a fully confluent monolayer of BCECs, they were placed in a 12-well plate containing a population of mixed glia cells, mainly astrocytes ${ }^{20}$. The medium was further supplemented with tight junction-inducing factors, where the medium in the top compartment consisted of $550 \mathrm{nM} \mathrm{HC}, 250 \mu \mathrm{M}$ CTP-cAMP, $17.5 \mu \mathrm{M}$ Ro 20-1724, and the medium in the bottom compartment consisted of a 1:1 mixture of endothelia medium and astrocyte condition medium supplemented with $550 \mathrm{nM} \mathrm{HC}$. The integrity of the BCEC monolayers was evaluated daily by measuring the transendothelial electrical resistance (TEER) using Millicell ERS-2 epithelial volt-ohm meter and STX01 Chopstick Electrodes (Merck Millipore, Hellerup, Denmark, DKThe measured TEER was subtracted from the value of an empty hanging insert containing culture medium, and the value multiplied by the area of the culture insert. The calculated TEER values were presented as mean $\Omega \times \mathrm{cm}^{2} \pm$ SD. Once the barrier was tight, half of the barriers were treated with 2 mM VPA added directly to the top chamber for 6 $\mathrm{h}$ or $24 \mathrm{~h}$.

Mixed glial cells were isolated as previously described ${ }^{20}$. The cells were resuspended in DMEM-F12 GlutaMAX medium supplemented with $10 \%$ FCS and $10 \mu \mathrm{g} / \mathrm{mL}$ gentamicin sulfate and seeded in flasks pre-coated with poly-L-lysine. The mixed glial cells were cultured for three weeks in an incubator at $5 \%$ $\mathrm{CO}_{2}$ and $37^{\circ} \mathrm{C}$. The cells were then frozen for later use in DMEM supplemented with $30 \% \mathrm{FCS}$ and $7.5 \%$ DMSO. The cells were then seeded in a poly-L-lysine coated 12-well plates and cultured 10 to 14 days until confluence.

\section{Probe-based RT-qPCR}

The purification of RNA from BCECs was carried out using the AllPrep DNA/RNA Mini kit following the manufacturer's protocol. RNA concentrations were assessed using DS-11 FX

Spectrophotometer/Fluorometer (DeNovix, USA). A total of $150 \mathrm{ng}$ RNA was treated with DNAse I enzyme to remove any potential genomic contamination, mixed with nuclease free water, $10 x$ reaction buffer and incubated for 30 minutes in a T100 Thermal cycler (Bio-rad) at $37^{\circ} \mathrm{C}$. All samples were then treated with Ethylenediaminetetraacetic acid (EDTA) for 10 minutes at $65^{\circ} \mathrm{C}$ to stop the reaction. Complementary DNA was generated using the RevertAid H Minus First Strand cDNA Synthesis Kit, which consisted of random hexamer primer, oligo primer, $10 \mathrm{mM}$ dNTP, $5 x$ reaction buffer and nuclease free water. This was mixed with Maxima $\mathrm{H}$ Enzyme mix and $100 \mathrm{ng}$ of DNase treated RNA and the samples run in the thermal cycler using the following thermal profile: 10 minutes at $25^{\circ} \mathrm{C}, 15$ minutes at $50^{\circ} \mathrm{C}$ and 5 minutes at $85^{\circ} \mathrm{C}$.

The RT-qPCR was carried out by preparing a mastermix containing the TaqMan Multiplex MasterMix and Taqman primer/probe for Glut1, CD98hc, TfR, Hprt1, and $1.7 \mathrm{ng}$ sample was added in each well. The samples were run on QuantStudio 6 Flex Real-Time PCR System (Thermo Fisher Scientific) with the thermal profile: $50^{\circ} \mathrm{C}$ for $2 \mathrm{~min}, 95^{\circ} \mathrm{C}$ for $20 \mathrm{~min}$, followed by 40 cycles of $95^{\circ} \mathrm{C}$ for 1 second and $60^{\circ} \mathrm{C}$ for 20 seconds. After the run, samples were cooled down to $20^{\circ} \mathrm{C}$. The relative mRNA expression was normalized to Hprt1 expression. 
Enzyme-linked immunosorbent assay (ELISA) was used to measure the amount of TfR, GLUT1 and CD98hc in isolated brain capillaries after VPA treatment to evaluate protein expression at the level of the $\mathrm{BBB}^{24}$. In order to account for varying protein concentrations in each sample, the total protein concentration was measured using BCA protein assay kit as previously described ${ }^{13}$. Each sample was lysed using $90 \mu \mathrm{L}$ N-per Neuronal protein extraction buffer supplemented with cOmplete Mini protease inhibitor. The samples were lysed on ice for $10 \mathrm{~min}$ and spun down at $14,000 \mathrm{~g}$ for $10 \mathrm{~min}$ at $4^{\circ} \mathrm{C}$ and the supernatant collected. Samples were diluted 1:10 in sample buffer and analyzed using sandwich-ELISA for mouse TfR 1 according to the manufacturer's protocol. The absorbance was read at $450 \mathrm{~nm}$ using an Enspire Plate Reader from Perkin Elmer, and the concentration calculated using a standard curve and normalized to the total protein concentration of each individual sample.

\section{Immunolabeling}

Immunohistochemistry was carried out to investigate the expression of TfR, GLUT1 and CD98hc in the brain capillaries. To block unspecific binding, the sections were incubated for $30 \mathrm{~min}$ in blocking buffer consisting of $0.01 \mathrm{M}$ PBS supplemented with $3 \%$ swine serum and $0.3 \%$ Triton X-100. The sections were incubated with primary antibodies at $4{ }^{\circ} \mathrm{C}$ on an orbital shaker overnight. The primary antibodies rat antimouse TfR1 (clone RI7217), rabbit anti-mouse Glut1 and rabbit anti-mouse CD98hc were diluted 1:200 in blocking buffer. The sections were washed three times and incubated for $30 \mathrm{~min}$ with Lycopersicon Esculentum (Tomato) Lectin Daylight 594 diluted 1:100 in blocking buffer and washed. The sections were then incubated for 30 min with secondary antibodies Alexa Flour 488 donkey anti-rat lgG and Alexa flour 488 goat anti-rabbit IgG were diluted 1:200 in blocking buffer, followed by 5 min incubation with DAPI diluted 1:500 in PBS. The sections were mounted onto slides using Dako Fluorescent mounting medium. Slides were examined on an AxioObserver Z1 fluorescence microscope equipped with ApoTome.2 and Axiocam MR camera under a Plan-Apochromat 20x/1.3 NA DIC objective. Images were corrected for brightness and contrast using the Image J software ${ }^{25}$.

As the expression of TfR1 in BCECs following VPA treatment proved particularly interesting, immunocytochemistry was performed on cultured BCECs to investigate the presence of TfR. Cells were also stained for the tight junction protein, zonula occludens-1 (ZO-1) to investigate if the cellular distribution was affected by the treatment. The medium was harvested, and the BCECs washed in $0.1 \mathrm{M}$ PBS, fixed for 10 min in $4 \%$ PFA and then washed twice in PBS. To block unspecific binding of antibodies, the cells were incubated for $30 \mathrm{~min}$ in $3 \%$ BSA and $0.3 \%$ Triton X-100 diluted in $0.1 \mathrm{M}$ PBS. BCECs were incubated for 60 min with rat anti-TfR1 (clone RI7217) and rabbit anti ZO-1 diluted 1:200 in blocking buffer. The cells were subsequently washed twice in washing buffer to remove any unbound primary antibodies. The cells were then incubated for $60 \mathrm{~min}$ with secondary antibodies Alexa Flour 594conjugated goat anti-rat and Alexa Flour 488-conjugated goat anti-rabbit diluted 1:200 in blocking buffer followed by washing. The nuclei were stained with DAPI for 5 min diluted 1:1000 in PBS. Cells were mounted onto slides using DAKO fluorescent mounting medium and examined using an AxioObserver Z1 
fluorescence microscope equipped with an ApoTome. 2 and Axiocam MR camera under a PlanApochromat 40x/1.3 NA oil DIC objective. Images were corrected for brightness and contrast using the ImageJ software ${ }^{25}$.

\section{Transcriptome sequencing}

We performed analysis of isolated capillaries in order to identify the potential effects VPA treatment might exert on the gene expression at the level of the BBB. Purified capillaries from six mice treated with either $100 \mathrm{mg} / \mathrm{kg}$ VPA or PBS for $6 \mathrm{~h}$ underwent transcriptome sequencing carried out by CeGat (CTS Classic Package). All samples went through the capillary depletion protocol, and the capillaries were purified using TRIzol Plus RNA Purification Kit following the manufacturer's protocol. The samples were then frozen to $-80^{\circ} \mathrm{C}$. Samples were sequenced for total RNA using NovaSeq $6000,2 x 100$ bp sequencing parameters. Bioinformatics analysis was carried out by CeGat. Briefly, raw data was normalized in $\mathrm{R}$

(version 3.6.1) and negative binomial generalized linear modelling was performed to identify differentially expressed genes (DEGs) between VPA and PBS treated mice using the DESeq2 (version 1.24.0) package. Genes with a value of $p \leq 0.05$ were chosen for further functional enrichment analysis of biological processes, which was carried out using GeneOntology.org powered by PANTHER using Fisher's Exact test (FDR $\leq$ 0.05). REVIGO (revigo.irb.hr) was used to reduce redundancy in the list of GO-terms, which were either close in $\mathrm{GO}$ hierarchy or related by inheritance 27 .

\section{Statistical analysis}

The relative gene expression of $T f r c$, Glut1, and Cd98hc mRNA from mice and isolated BCECs was calculated according to the Pfaffl method ${ }^{27}$. All data was checked for normal distribution before performing statistical analysis. The results were analyzed using one-way ANOVA with Dunnett's multiple comparisons test in GraphPad Prism 9. When investigating the difference in mRNA expression between male and female mice, a two-way ANOVA with the Holm-Sidak multiple comparisons test was used. ELISA data on the expression of TfR1, GLUT1 and CD98Hc in brain capillaries was analyzed by one-way ANOVA with Dunnett's multiple comparisons test. The luminal binding of Nanogold-conjugated anti-TfR1 antibodies was analyzed by unpaired t-test. Significance levels were ${ }^{*} p=0.01-0.05,{ }^{*} p=0.001-0.01$,

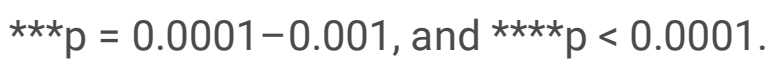

\section{Results}

\section{VPA causes upregulation of Tfrc in BCECs in vitro}

To evaluate the effects of VPA on the expression of important drug delivery targets on the BCECs, BCECs co-cultured with mixed glial cells were treated with $2 \mathrm{mM}$ VPA for $6 \mathrm{~h}$ or $24 \mathrm{~h}$. The integrity of the barriers was evaluated via measurement of TEER and immunolabeling of the tight junction associated protein, ZO-1. The TEER was unaffected by VPA treatment both after $6 \mathrm{~h}$ and $24 \mathrm{~h}$ (Fig. 1A-B) and the expression and subcellular distribution of ZO-1 were similar between the control barriers (Fig. 1F) and the barriers treated with VPA for $24 \mathrm{~h}$ (Fig. 1J). 
Having established that the VPA treatment did not affect the integrity of the in vitro barriers, we then analyzed the effect of VPA treatment on the expression profiles of Tfrc, Glut1, and Cd98hc. genes. The mRNA expression of Tfrc was significantly higher after VPA treatment for $6 \mathrm{~h}$, and the expression level returned to baseline after $24 \mathrm{~h}$ (Fig. 1C). Conversely, the mRNA expression of Glut1 and Cd98hc was unaffected by VPA treatment (Fig. 1D-E).

Furthermore, VPA not only increased the mRNA expression of Tfrc but also the protein expression of TfR1 as the immunolabelling of TfR1 showed increased TfR1 signal particularly in the perinuclear region of the BCECs suggestive of increased presence of TfR1 in granular endoplasmic reticulum (GER) compared to the control BCECs (Figs.11,M).

\section{VPA induces TfR 1 expression in vivo}

We next wanted to investigate if VPA had the same effects on gene and protein expression of TfR1, GLUT1, and CD98hc in living animals as in the in vitro cultured BCECs. Validating the effects of VPA on gene transcription in isolated capillaries, the transcriptomic analysis identified 24,371 expressed genes, of which 305 were differentially expressed $(p \leq 0.05)$ with 192 upregulated and 113 downregulated genes (Suppl. Fig. S1). Furthermore, the functional enrichment analysis of GO biological processes showed 102 significant pathways (FDR $\leq 0.05)$ genes (Suppl. Fig. S2).

Analyzing the isolated brain capillaries from PBS, $100 \mathrm{mg} / \mathrm{kg}$ VPA, and $400 \mathrm{mg} / \mathrm{kg}$ VPA treated animals, the expression of Tfrc was unaltered between treatment groups $24 \mathrm{~h}$ post injection (Fig. 2A) and there was no difference in expression between male and female mice (Fig. 2B). However, the TfR1 protein expression in capillaries increased significantly after treatment with both $100 \mathrm{mg} / \mathrm{kg}$ and $400 \mathrm{mg} / \mathrm{kg}$ VPA (Figs. 2A,2C) (Fig. 2A). The TfR1 level ranged from 1.5 to $3,7 \mathrm{ng} / \mu \mathrm{g}$ protein and was not impacted by the gender of the animals (Fig. 2D). Using immunohistochemistry, the TfR1 was expressed on BCECs and neurons (Fig. 2E-G) as previously described ${ }^{28,29}$. The TfR1 expression co-localized with lectin in the vascular segments (Fig. 2F-G).

\section{VPA increases Glut1 mRNA in male, but not in female mice}

The mRNA expression of G/ut1 in isolated capillaries was unaffected by treatment with $100 \mathrm{mg} / \mathrm{kg}$ and $400 \mathrm{mg} / \mathrm{kg}$ VPA for 24 hours (Fig. 3). However, when considering gender-related differences male mice treated with $400 \mathrm{mg} / \mathrm{kg}$ VPA for 24 hours significantly upregulated their expression of G/ut1 compared to the PBS treated male mice (Fig. 3B). The increased expression of G/ut1 mRNA among the $400 \mathrm{mg} / \mathrm{kg}$ VPA treated male mice was not reflected in the GLUT1 protein expression, as the GLUT1 protein expression was unchanged in all treatment groups (Fig. C-D). Using immunohistochemistry, GLUT1 evidently colocalized with lectin indicating its confinement to brain capillaries (Fig. F-G). 
The mRNA expression of Cd98hc was unaltered between the control mice and the VPA-treated mice, and no difference was observed between male and female mice (Fig. 2A-B). The CD98hc displayed high level of protein expression in capillaries, ranging from 1.8-3.7 $\mathrm{ng} / \mathrm{mg}$ protein (Fig 2C-D), however, we were unable to obtain reliable results using a commercial antibody raised against CD98hc showing expression in BCECs (not shown), and we therefore declined further interpretation concerning expression of CD98hc in BCECs at the morphological level.

\section{Uptake of gold-labeled anti-TfR1 antibodies}

Next, we wanted to study, whether the increased TfR1 expression in brain capillaries induced by VPA could be quantitatively reflected by increased uptake of gold-labeled anti-TfR1 antibodies. We administered the antibodies intravenously at a dose of $1 \mathrm{mg} / \mathrm{kg}$ to VPA-treated ( $100 \mathrm{mg} / \mathrm{kg}$ for 24 hours) and control male mice and allowed them to circulate for $30 \mathrm{~min}$. Using ICP-MS-based quantification of the gold content, the brain accumulation was non-significant suggesting that VPA treatment did not improve the uptake of the anti-TfR1 antibodies in spite increased expression of TfR1 (Fig. 5A). Similarly, the uptake of the gold-labeled anti-TfR1 antibodies in liver, lung and spleen, organs in where TfR1 is mainly expressed in hepatocytes (Fig. 5B), and macrophages (Figs. 5C-D) was unaltered.

\section{Discussion}

Targeting nutrient receptors and transporters which are highly expressed at the BBB is of interest for delivery of large therapeutics to the brain. These transporting molecules follow Michaelis-Menten type kinetics with the maximum transport capacity being reflected in their surface availability ${ }^{30}$, which led to the question if it would be possible to increase the expression of TfR1, GLUT1 or CD98hc on the BCECs by epigenetic mechanisms leading to increases at the surface availability and transport of targeted molecules.

In addition to investigating the transcriptional alteration of TfR1, GLUT1, and CD98hc, we carried out transcriptome sequencing on brain capillaries to further understand the broad effect of VPA. VPA inhibits the histone deacetylation process, thereby ensuring the accessibility of transcription factors to the chromatin, which increases gene transcription of multiple genes and therefore not specific for the aforementioned targets ${ }^{12,31,32}$.

VPA is known to interact at the level of the BBB, e.g. VPA prevents BBB disruption after subarachnoid hemorrhage $^{33}$ and intracerebral hemorrhage ${ }^{34}$, and it lessens BBB disruption after transient focal cerebral ischemia ${ }^{35}$. VPA was initially approved as an anti-epileptic drug, but its ability to inhibit HDAC could explain the increase in TfR1 observed in the current study ${ }^{36}$.

TfR1 remains the most studied receptor for targeting the $\mathrm{BBB}^{29}$. The reason for its popularity is that TfR1 is only expressed on BCECs and not on other endothelial cells in the body ${ }^{29}$, which could lead to a preferential cerebral accumulation of TfR1 targeted molecules ${ }^{29,38}$. TfR1 promotes the uptake of 
transferrin-bound iron, which is an essential co-factor in multiple physiological functions such as cell division, DNA synthesis, and oxygen transport ${ }^{39-44}$. We found that VPA treatment increases the expression of Tfrc significantly after 6 hours in vitro, reaching an expression of three times above that of the controls, and that the expression was back to baseline after 24 hours of treatment. To examine whether this effect was species-specific, we conducted similar experiments in the rat, which increased the expression of Tfrc with 2,5-fold following VPA treatment ${ }^{45}$.

The increased expression of Tfrc transcript translated to higher TfR1 protein expression in vitro. In order to explore whether this upregulation of TfR 1 corresponded to increased expression in BCECs in vivo, the expression of Tfrc mRNA was investigated in purified brain capillaries from mice treated with VPA for 24 hours. However, there was no indication of altered expression of Tfrc $24 \mathrm{~h}$ post injection. Whether expression of $T$ frc is regulated by post-transcriptional mechanisms rather than regulation of its synthesis of its $\mathrm{mRNA}^{46}$, meaning that in conditions with e.g. deprivation of nutritional iron-supply, cells upregulate TfR1 protein by increasing translation of its mRNA remains to be answered. Here we demonstrate an increase in Tfrc expression in vitro following $6 \mathrm{~h}$ treatment with VPA, whereas the expression is back to baseline after $24 \mathrm{~h}$.

In BCECs, the content of TfR1 is particular high during formation of the brain and ceases with increasing postnatal age ${ }^{47-49}$. In the rat, this was also reflected in a developmentally higher uptake of ironcontaining transferrin and a monoclonal antibody (OX26) targeting TfR1 following intravenously injection ${ }^{50}$. The current study suggests that VPA also leads to increased post-translational expression of TfR1 in BCECs.

In terms of the functioning of TfR1 for uptake of iron-containing transferrin at the BBB, it may seem a paradox that in conditions with iron deficiency, the adult brain far from increases the expression of TfR1 in BCECs, when compared to the much higher expression during early postnatal development. Prior studies in isolated porcine BCECs suggest that BCECs harbor a significant spare pool of transferrin receptors that can be mobilized when needed as occurring in conditions with cerebral iron-deficiency ${ }^{51,52}$. The present study examining adult mice did not record an increased uptake of 1,4 nm gold-conjugated anti-transferrin receptor antibodies in spite a higher content of TfR1 following VPA treatment. This absence suggests that the quantity of functionally available TfR1 molecules contributing to cellular uptake of the targeted anti-TfR1 antibody remained unaltered in BCECs following VPA treatment. This also suggests that the observed increased expression of TfR1 protein in BCECs following VPA treatment attributes to an enlargement of the intracellular TfR1 pool. Possibly the BCECs' uptake of iron-transferrin and targeted antibodies in adults operates primarily via mobilization of this intracellular pool of spare TfR1, which could get contribution from the pharmacologically enhanced expression of TfR1 protein.

When looking at the overall expression of GLUT1 or CD98hc in the current study, no difference could be detected in mice after VPA treatment. The expression of GLUT1 in brain is selectively confined to BCECs and among the most abundant proteins in BCECs ${ }^{53-55}$. GLUT1 expression is regulated in accordance to the brains' metabolic needs, and a reduction was observed in Alzheimer's disease ${ }^{55-57}$. However, when 
dividing the animals to groups dependent on gender, there was a significantly higher expression of Glut1 in the brains of male mice that had been treated with VPA.

CD98hc has been identified as a potential interesting molecule for pharmacological targeting to the $\mathrm{BBB}^{14,58-60}$. CD98hc is an intracellular amino acid transporter and integrin signaling enhancer ${ }^{14}$ and among the most highly expressed transcripts in human and mouse brain capillaries ${ }^{59,60}$, which is in agreement with the high expression of CD98hc protein detected in the ELISA of the present study.

\section{Conclusions}

The current study showed that it is possible to upregulate the expression of TfR1 protein in BCECs utilizing epigenetic mechanisms, in this case the histone deacetylase inhibitor VPA. Epigenetic upregulation was not seen for GLUT1 or CD98hc, two other major molecular targets for drug delivery to the BBB. The increase in the overall TfR1 protein expression did not lead to increased transport of TfRtargeted Ri7 antibody, which suggests that targeted delivery to the BBB using TfR1 should rather aim for increased mobilization of already available transferrin receptor molecules to improve trafficking through the BBB.

\section{Abbreviations}

BBB Blood-brain barrier

BCECs Brain capillary endothelial cells

CD98hc Cluster of Differentiation 98 Heavy Chain

Glut1 Glucose transporter 1

TEER Transendothelial electrical resistance

TfR Transferrin receptor

VPA Valproic acid

ZO-1 Zonula occludens 1

\section{Declarations}

\section{Acknowledgements}

We thank Merete Fredsgaard and Hanne Krone Nielsen, Aalborg University, Denmark, for their excellent technical assistance.

\section{Funding Information}


The present study has been supported by the Lundbeck Foundation Research Initiative on Brain Barriers and Drug Delivery (Grant no. R155-2013-14113), the Danish Multiple Sclerosis Society (Grant no. A38230), and Svend Andersen Fonden.

\section{References}

1 Abbott NJ. Blood-brain barrier structure and function and the challenges for CNS drug delivery. $J$ Inherit Metab Dis 2013; 36: 437-449.

2 Pardridge WM. Blood-Brain Barrier and Delivery of Protein and Gene Therapeutics to Brain. Front. Aging Neurosci. 2020; 11. doi:10.3389/fnagi.2019.00373.

3 Mills E, Dong X-P, Wang F, Xu H. Mechanisms of brain iron transport: insight into neurodegeneration and CNS disorders. Future Med Chem 2010; 2: 51-64.

4 Abbott NJ, Rönnbäck L, Hansson E. Astrocyte-endothelial interactions at the blood-brain barrier. Nat Rev Neurosci 2006; 7: 41-53.

5 Abbott NJ, Patabendige AAK, Dolman DEM, Yusof SR, Begley DJ. Structure and function of the blood-brain barrier. Neurobiol Dis 2010; 37: 13-25.

6 Daneman R, Prat A. The blood-brain barrier. Cold Spring Harb Perspect Biol 2015; 7. doi:10.1101/cshperspect.a020412.

7 Greene C, Hanley N, Campbell M. Claudin-5: gatekeeper of neurological function. Fluids Barriers CNS 2019; 16: 3.

8 Reese TS, Karnovsky MJ. Fine structural localization of a blood-brain barrier to exogenous peroxidase. J Cell Biol 1967; 34: 207-217.

9 Zlokovic B V. The Blood-Brain Barrier in Health and Chronic Neurodegenerative Disorders. Neuron 2008; 57: 178-201.

10 Kevadiya BD, Ottemann BM, Thomas M Ben, Mukadam I, Nigam S, McMillan JE et al. Neurotheranostics as personalized medicines. Adv Drug Deliv Rev 2018. doi:10.1016/j.addr.2018.10.011.

11 Moura RP, Martins C, Pinto S, Sousa F, Sarmento B. Blood-brain barrier receptors and transporters: an insight on their function and how to exploit them through nanotechnology. Expert Opin. Drug Deliv. 2019; 16: 271-285.

12 Bhatti UF, Williams AM, Georgoff PE, Alam HB. The 'Omics' of Epigenetic Modulation by Valproic Acid Treatment in Traumatic Brain Injury-What We Know and What the Future Holds. Proteomics - Clin. Appl. 2019; 13. doi:10.1002/prca.201900068. 
13 Helgudottir SS, Routhe LJ, Burkhart A, Jønsson K, Pedersen IS, Lichota J et al. Epigenetic Regulation of Ferroportin in Primary Cultures of the Rat Blood-Brain Barrier. Mol Neurobio/ 2020; 57: 3526-3539.

14 Zuchero YJY, Chen X, Bien-Ly N, Bumbaca D, Tong RK, Gao X et al. Discovery of Novel Blood-Brain Barrier Targets to Enhance Brain Uptake of Therapeutic Antibodies. Neuron 2016; 89: 70-82.

15 Long Z, Zeng Q, Wang K, Sharma A, He G. Gender difference in valproic acid-induced neuroprotective effects on APP/PS1 double transgenic mice modeling Alzheimer's disease. Acta Biochim Biophys Sin (Shanghai) 2016; 48: 930-938.

16 Ibarra M, Vázquez M, Fagiolino P, Derendorf $\mathrm{H}$. Sex related differences on valproic acid pharmacokinetics after oral single dose. J Pharmacokinet Pharmacodyn 2013; 40: 479-486.

17 Chaliha D, Albrecht M, Vaccarezza M, Takechi R, Lam V, Al-Salami H et al. A Systematic Review of the Valproic-Acid-Induced Rodent Model of Autism. Dev Neurosci 2020; 42: 12-48.

18 Johnsen KB, Bak M, Kempen PJ, Melander F, Burkhart A, Thomsen MS et al. Antibody affinity and valency impact brain uptake of transferrin receptor-targeted gold nanoparticles. Theranostics 2018; 8 : 3416-3436.

19 Kucharz K, Kristensen K, Johnsen KB, Lund MA, Lønstrup M, Moos T et al. Post-capillary venules are the key locus for transcytosis-mediated brain delivery of therapeutic nanoparticles. Nat Commun 2021; 12. doi:10.1038/S41467-021-24323-1.

20 Thomsen MS, Birkelund S, Burkhart A, Stensballe A, Moos T. Synthesis and deposition of basement membrane proteins by primary brain capillary endothelial cells in a murine model of the blood-brain barrier. J Neurochem 2017; 140: 741-754.

21 Thomsen MS, Humle N, Hede E, Moos T, Burkhart A, Thomsen LB. The blood-brain barrier studied in vitro across species. PLoS One 2021; 16. doi:10.1371/journal.pone.0236770.

22 Perrière N, Demeuse PH, Garcia E, Regina A, Debray M, Andreux JP et al. Puromycin-based purification of rat brain capillary endothelial cell cultures. Effect on the expression of blood-brain barrierspecific properties . J Neurochem 2005; 93: 279-289.

23 Calabria AR, Weidenfeller C, Jones AR, De Vries HE, Shusta E V. Puromycin-purified rat brain microvascular endothelial cell cultures exhibit improved barrier properties in response to glucocorticoid induction. J Neurochem 2006; 97: 922-933.

24 Hill JJ, Haqqani AS, Stanimirovic DB. Proteome of the Luminal Surface of the Blood-Brain Barrier. Proteomes 2021; 10: 45. doi: 10.3390/proteomes 9040045 . 
25 Schindelin J, Arganda-Carreras I, Frise E, Kaynig V, Longair M, Pietzsch T et al. Fiji: an open-source platform for biological-image analysis. Nat Methods 2012; 9: 676-682.

26 Supek F, Bošnjak M, Škunca N, Šmuc T. REVIGO Summarizes and Visualizes Long Lists of Gene Ontology Terms. PLoS One 2011; 6: e21800.

27 Pfaffl MW. A new mathematical model for relative quantification in real-time RT-PCR. Nucleic Acids Res 2001; 29: e45.

28 Moos T. Immunohistochemical localization of intraneuronal transferrin receptor immunoreactivity in the adult mouse central nervous system - Moos - 1996 - Journal of Comparative Neurology - Wiley Online Library. J Comp Neurol 1996; 375: 675-692.

29 Jefferies WA, Brandon MR, Hunt S V., Williams AF, Gatter KC, Mason DY. Transferrin receptor on endothelium of brain capillaries. Nature 1984; 312: 162-163.

30 Christian H, Helms C, Kristensen M, Saaby L, Fricker G, Brodin B. Drug Delivery Strategies to Overcome the Blood-Brain Barrier (BBB). doi:10.1007/164_2020_403.

31 Hwang JY, Aromolaran KA, Zukin RS. The emerging field of epigenetics in neurodegeneration and neuroprotection. Nat. Rev. Neurosci. 2017; 18: 347-361.

32 Bowman GD, Poirier MG. Post-translational modifications of histones that influence nucleosome dynamics. Chem. Rev. 2015; 115: 2274-2295.

33 Ying GY, Jing CH, Li JR, Wu C, Yan F, Chen JY et al. Neuroprotective Effects of Valproic Acid on Blood-Brain Barrier Disruption and Apoptosis-Related Early Brain Injury in Rats Subjected to Subarachnoid Hemorrhage Are Modulated by Heat Shock Protein 70/Matrix Metalloproteinases and Heat Shock Protein 70/AKT Pathways. Neurosurgery 2016; 79: 286-295.

34 Zhao W, Zhao L, Guo Z, Hou Y, Jiang J, Song Y. Valproate Sodium Protects Blood Brain Barrier Integrity in Intracerebral Hemorrhage Mice. Oxid Med Cell Longev 2020; 2020. doi:10.1155/2020/8884320.

35 Wang Z, Leng Y, Tsai LK, Leeds P, Chuang DM. Valproic acid attenuates blood-brain barrier disruption in a rat model of transient focal cerebral ischemia: the roles of HDAC and MMP-9 inhibition. $J$ Cereb Blood Flow Metab 2011; 31: 52-57.

36 Ornoy A, Becker M, Weinstein-Fudim L, Ergaz Z. S-Adenosine Methionine (SAMe) and Valproic Acid (VPA) as Epigenetic Modulators: Special Emphasis on their Interactions Affecting Nervous Tissue during Pregnancy. Int J Mol Sci 2020; 21. doi:10.3390/IJMS21103721.

37 Johnsen KB, Burkhart A, Melander F, Kempen PJ, Vejlebo JB, Siupka P et al. Targeting transferrin receptors at the blood-brain barrier improves the uptake of immunoliposomes and subsequent cargo 
transport into the brain parenchyma. Sci Rep 2017. doi:10.1038/s41598-017-11220-1.

38 Zhang W, Liu QY, Haqqani AS, Leclerc S, Liu Z, Fauteux F, et al. Differential expression of receptors mediating receptor-mediated transcytosis (RMT) in brain microvessels, brain parenchyma and peripheral tissues of the mouse and the human. Fluids Barriers CNS. 2020; 22: 47. doi: 10.1186/s12987-020-002090 .

39 Crielaard BJ, Lammers T, Rivella S. Targeting iron metabolism in drug discovery and delivery. Nat Publ Gr 2017; 16. doi:10.1038/nrd.2016.248.

40 Drakesmith H, Nemeth E, Ganz T. Ironing out Ferroportin. Cell Metab 2015; 22: 777-787.

41 Gulec S, Anderson GJ, Collins JF. Mechanistic and regulatory aspects of intestinal iron absorption. Am J Physiol Gastrointest Liver Physiol 2014; 307. doi:10.1152/AJPGI.00348.2013.

42 Belaidi AA, Bush Al. Iron neurochemistry in Alzheimer's disease and Parkinson's disease: targets for therapeutics. J Neurochem 2016; 139 Suppl 1: 179-197.

43 Silva B, Faustino P. An overview of molecular basis of iron metabolism regulation and the associated pathologies. Biochim Biophys Acta 2015; 1852: 1347-1359.

44 Duck KA, Connor JR. Iron uptake and transport across physiological barriers. BioMetals 2016294 2016; 29: 573-591.

45 Helgudottir SS. Expressional prerequisites for targeted drug delivery to the pathological brain. Aalborg University. Faculty of Health. Ph.D.-Series, 2021.

46 Rouault TA. The role of iron regulatory proteins in mammalian iron homeostasis and disease. Nat Chem Biol 2006; 2: 406-414.

47 Morgan EH, Moos T. Mechanism and developmental changes in iron transport across the bloodbrain barrier. Dev Neurosci 2002; 24: 106-113.

48 Moos T, Oates PS, Morgan EH. Expression of the neuronal transferrin receptor is age dependent and susceptible to iron deficiency. J Comp Neuro/ 1998; 398: 420-430.

49 Taylor EM, Crowe A, Morgan EH. Transferrin and iron uptake by the brain: effects of altered iron status. J Neurochem 1991; 57: 1584-1592.

50 Moos T, Morgan EH. Restricted transport of anti-transferrin receptor antibody (OX26) through the blood-brain barrier in the rat. $J$ Neurochem 2001; 79: 119-129.

51 Chiou B, Neal EH, Bowman AB, Lippmann ES, Simpson IA, Connor JR. Endothelial cells are critical regulators of iron transport in a model of the human blood-brain barrier. J Cereb Blood Flow Metab. 2019: 39 :2117-2131. doi: 10.1177/0271678X18783372. 
52 Van Gelder W, Huijskes-Heins MIE, Van Dijk JP, Cleton-Soeteman MI, Van Eijk HG. Quantification of different transferrin receptor pools in primary cultures of porcine blood-brain barrier endothelial cells. $J$ Neurochem 1995; 64: 2708-2715.

53 Daneman R, Zhou L, Agalliu D, Cahoy JD, Kaushal A, Barres BA. The mouse blood-brain barrier transcriptome: a new resource for understanding the development and function of brain endothelial cells. PLoS One 2010; 5: e13741.

54 Simpson IA, Carruthers A, Vannucci SJ. Supply and demand in cerebral energy metabolism: the role of nutrient transporters. J Cereb Blood Flow Metab 2007; 27: 1766-1791.

55 Simpson IA, Vannucci SJ, DeJoseph MR, Hawkins RA. Glucose transporter asymmetries in the bovine blood-brain barrier. J Biol Chem 2001; 276: 12725-12729.

56 Xiuli G, Meiyu G, Guanhua D. Glucose transporter 1, distribution in the brain and in neural disorders: its relationship with transport of neuroactive drugs through the blood-brain barrier. Biochem Genet 2005; 43: $175-187$.

57 Winkler EA, Nishida Y, Sagare AP, Rege S V., Bell RD, Perlmutter D et al. GLUT1 reductions exacerbate Alzheimer's disease vasculo-neuronal dysfunction and degeneration. Nat Neurosci 2015; 18: $521-530$.

58 Keaney J, Campbell M. The dynamic blood-brain barrier. FEBS J 2015; 282: 4067-4079.

59 Uchida Y, Ohtsuki S, Katsukura Y, Ikeda C, Suzuki T, Kamiie J et al. Quantitative targeted absolute proteomics of human blood-brain barrier transporters and receptors. J Neurochem 2011; 117: 333-345.

60 Zhang W, Liu QY, Haqqani AS, Leclerc S, Liu Z, Fauteux F et al. Differential expression of receptors mediating receptor-mediated transcytosis (RMT) in brain microvessels, brain parenchyma and peripheral tissues of the mouse and the human. Fluids Barriers CNS 2020; 17: 1-17.

\section{Figures}



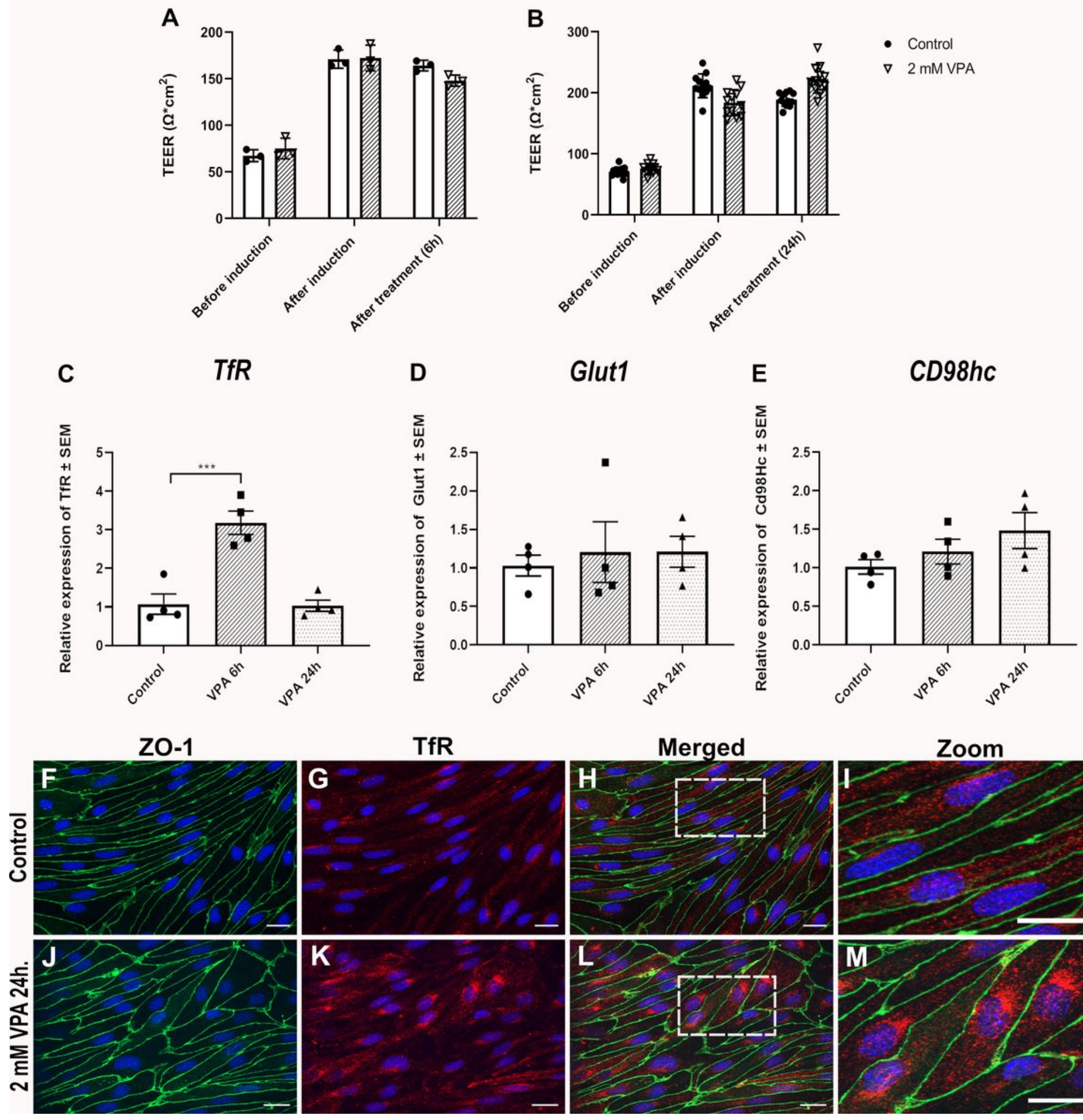

TfR
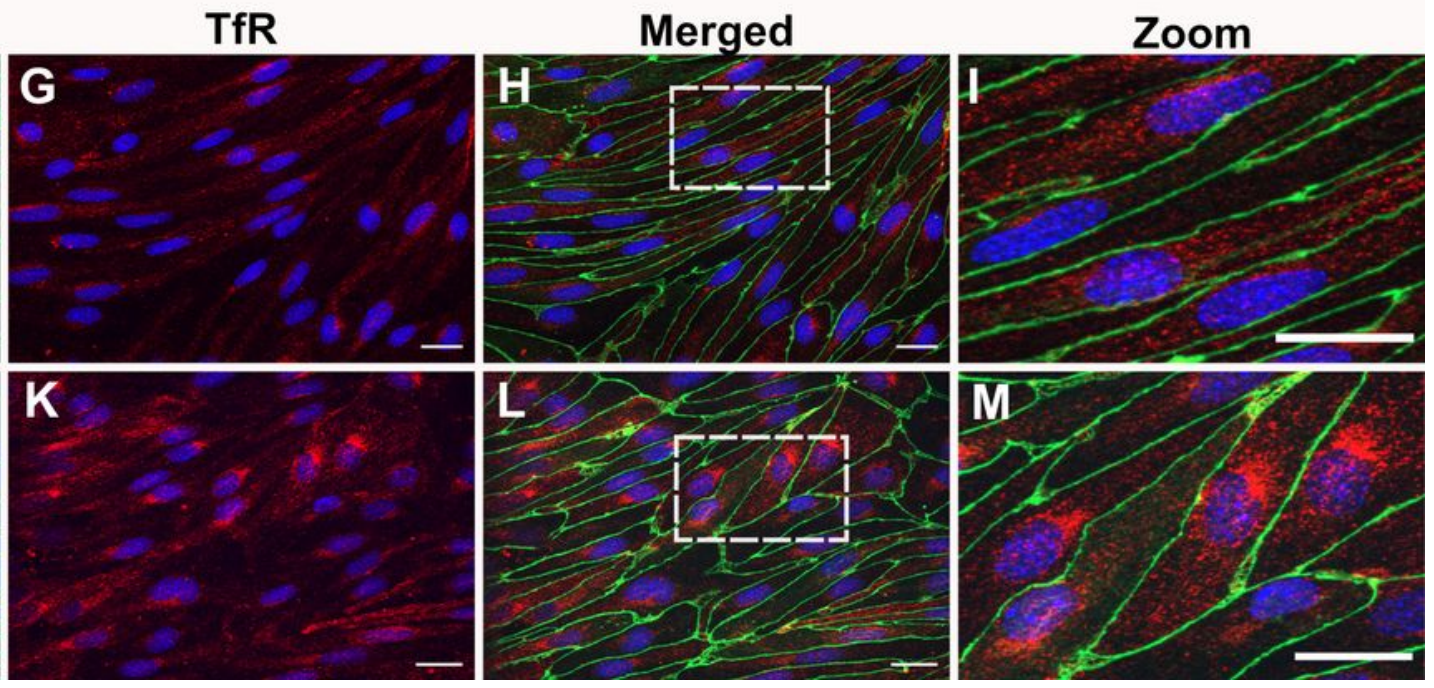

Figure 1

In vitro experiments addressing the effects of valproic acid (VPA) on mRNA expression of Tfrc, Glut1, and Cd98hc. (A-B) The transendothelial electrical resistance (TEER) was investigated before and after tight junction induction expression, as well as treatment with VPA for $6(n=3)(A)$ and $24(n=12)(B)$ hours $(h)$. After induction of BBB properties, the tightness of the barrier remains intact even after treatment with VPA for $24 \mathrm{~h}$. The expression of Tfrc mRNA in BCECs increases after $6 \mathrm{~h}$ of treatment with VPA and returns to 
baseline after $24 \mathrm{~h}$ (C). There are no changes in mRNA expression of Glut7 (D) or CD98hc (E) following VPA treatment. A change in gene expression is analyzed using one-way ANOVA with Dunnett's multiple comparisons test. Data $(n=4)$ are shown as mean $\pm S E M, * \star * p=0.0001-0.001$. (F-M) Immunocytochemistry showing zonula occludens (ZO-1; green) and TfR1 (red) expression in BCECs cocultured with mixed glia cells and treated with PBS (F-I) or 2 mM VPA (J-M). The tight junction protein ZO1 remains highly expressed in spite of treatment with VPA (compare F with $\mathrm{J}$ ). Morphologically, the increased mRNA expression of Tfrc translates to increased TfR1 protein expression (compare G-I and K$M)$. When shown in high magnification (I and $M$ ), it is evident that the TfR1 protein is highly expressed after VPA treatment revealing a perinuclear distribution, which probably reflects the higher synthesis in granular endoplasmic reticulum. The nuclei are stained with DAPI (blue). Scale bar: $20 \mu \mathrm{m}$. 
A

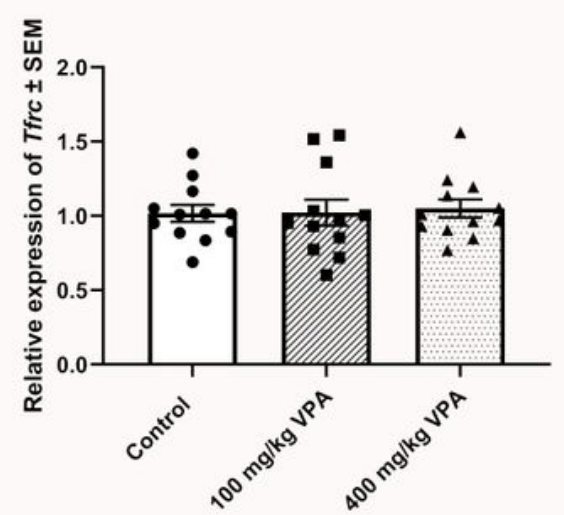

C
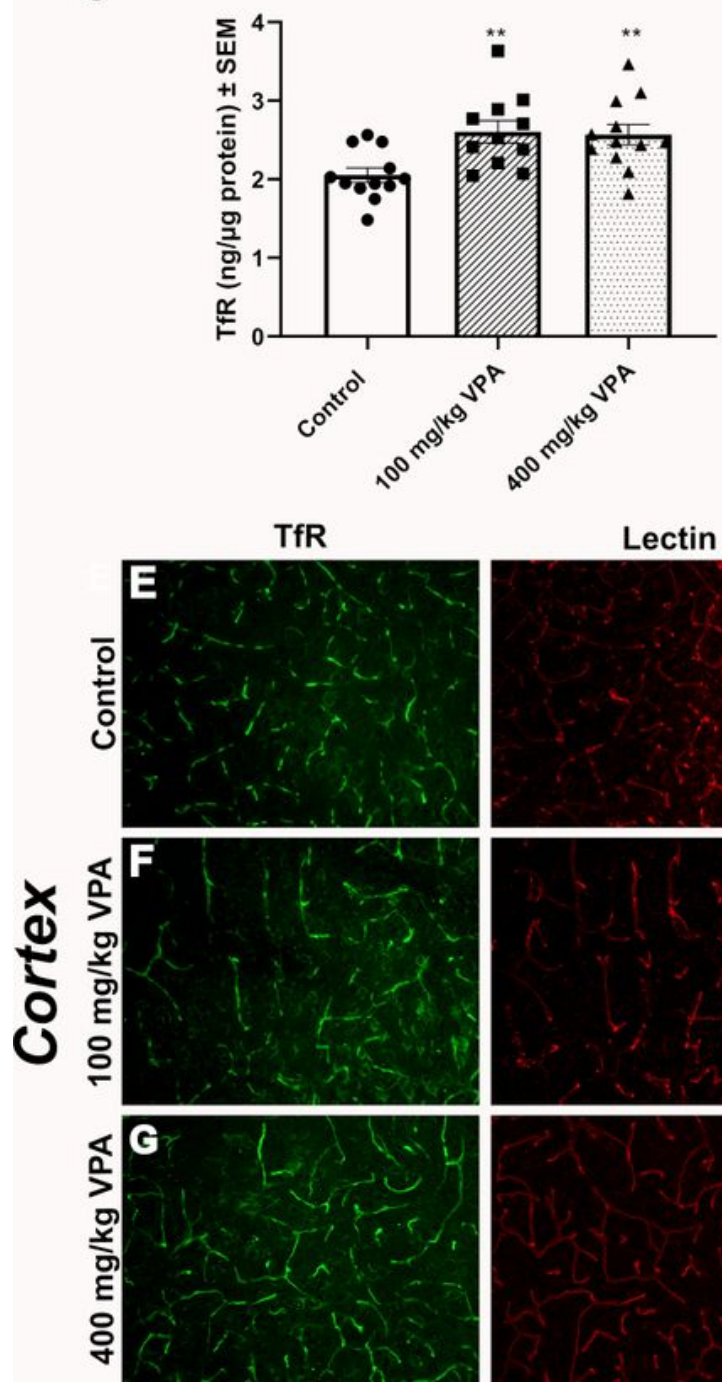

B

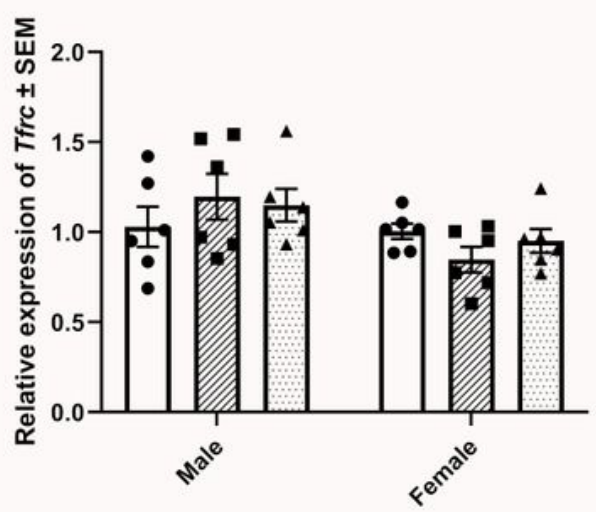

D

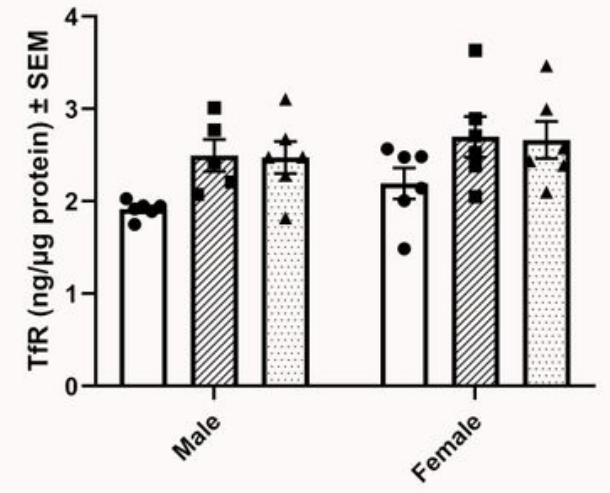

Merged
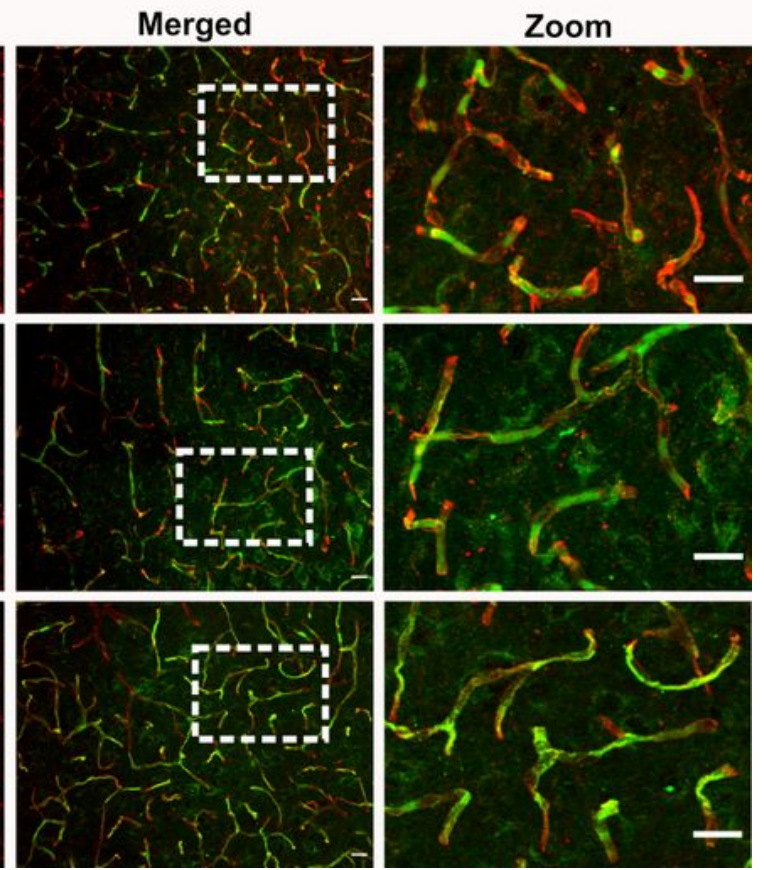

Figure 2

Expression of TfR1 in brain capillaries after valproic acid (VPA) treatment. (A.) Tfrc mRNA expression in capillary depleted brain extracts from mice treated with PBS ( $n=12), 100 \mathrm{mg} / \mathrm{kg}$ VPA $(n=12)$, or 400 $\mathrm{mg} / \mathrm{kg}$ VPA $(\mathrm{n}=12)$ for 24 hours. (B.) The Tfrc expression profile separated based on sex (males $n=6$ and females $n=6$ for each treatment group). A change in gene expression is analyzed using one-way ANOVA with Dunnett's multiple comparisons and when investigating the difference in mRNA expression between 
male and female mice, a two-way ANOVA with the Holm-Sidak multiple comparisons test is used. Data $(n=6-12)$ are shown mean \pm SEM. No differences are observed in Tfrc mRNA expression in the group of all animals (A) or after division by sex (B). (C-D) In contrast, when analyzed for TfR1 protein in isolated capillaries, both $100 \mathrm{mg}(\mathrm{n}=11)$ and $400 \mathrm{mg}(\mathrm{n}=12)$ VPA treatment for 24 hours significantly increase TfR1 protein expression (C) with similar upregulation in male and female mice (B). One-way ANOVA with Dunnett's multiple comparisons test was used for statistical analysis. ${ }^{\star \star} p=0.001-0.01$. Data $(n=11-12)$ are depicted as mean \pm SEM. (E-G) Representative images of immunohistochemical detection of TfR1 expression in cerebral cortex of mice injected with PBS (E) or VPA in concentrations of $100 \mathrm{mg} / \mathrm{kg}(\mathrm{F})$ or $400 \mathrm{mg} / \mathrm{kg}(\mathrm{G})$ allowed to circulate for 24 hours. TfR1 is expressed in brain capillaries co-localizing with tomato lectin (red) that labels the brain capillaries and in cortical neurons Scale bar: $20 \mu \mathrm{m}$. 
A
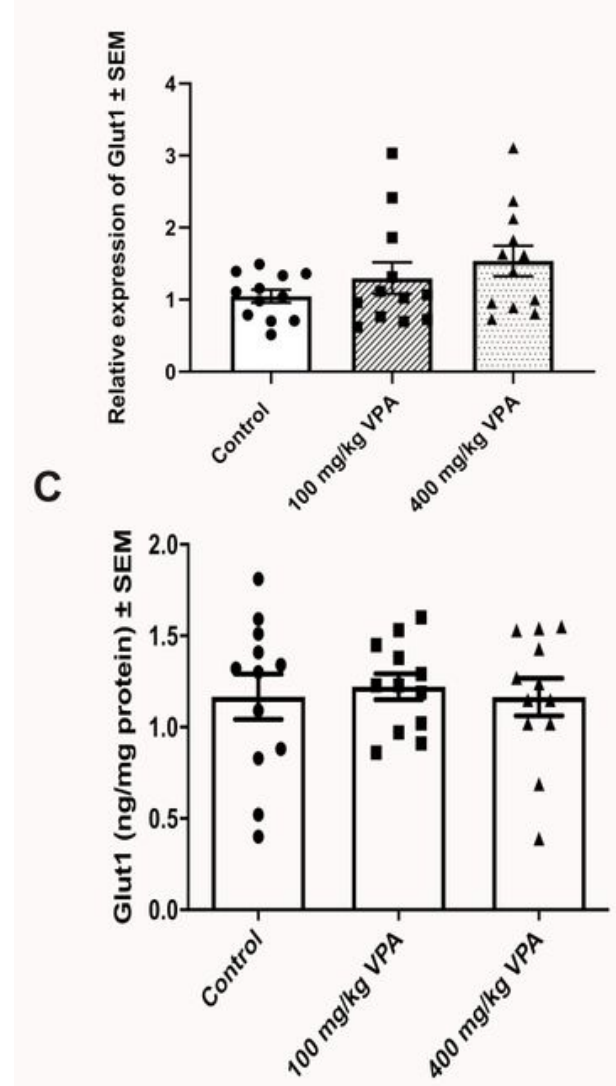

B

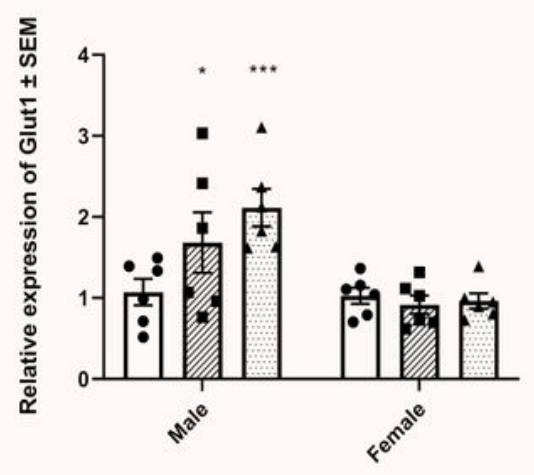

D

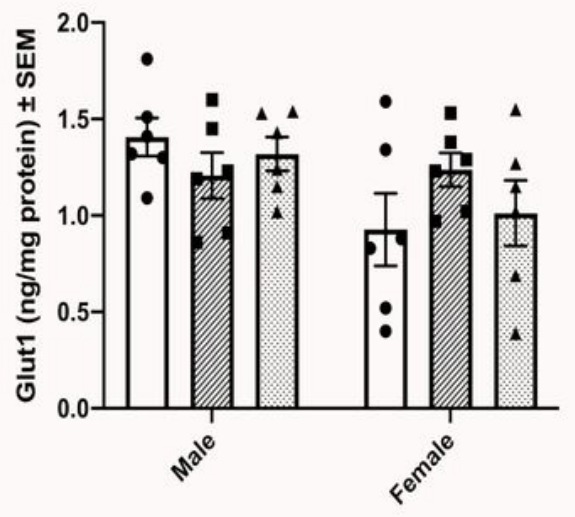

Merged
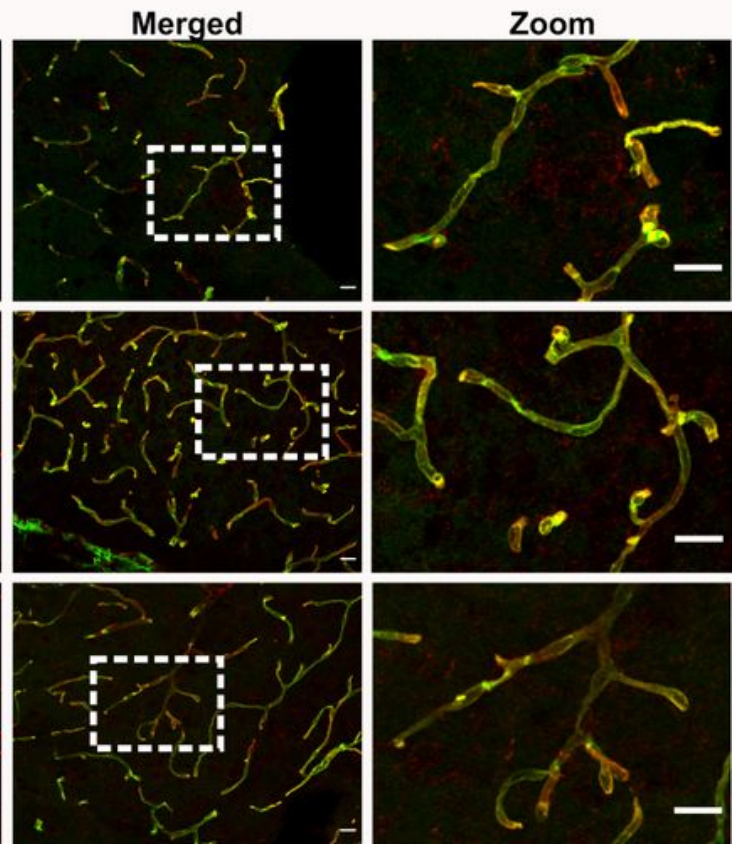

\section{Figure 3}

Expression of GLUT1 in brain capillaries after valproic acid (VPA) treatment. (A) Glut1 mRNA expression in capillary depleted brain extracts from mice treated with PBS $(n=12), 100 \mathrm{mg} / \mathrm{kg}$ VPA $(n=12)$, or 400 $\mathrm{mg} / \mathrm{kg}$ VPA ( $\mathrm{n}=12)$ for 24 hours. (B.) The Glut1 expression profile separated based on sex (males $\mathrm{n}=6$ and females $n=6$ for each treatment group). A change in gene expression is analyzed using one-way ANOVA with Dunnett's multiple comparisons and when investigating the difference in mRNA expression between 
male and female mice, a two-way ANOVA with the Holm-Sidak multiple comparisons test is used. Data $(n=6-12)$ are shown mean $\pm S E M, * * p=0.001-0.01$. No differences are observed in G/ut1 mRNA in the group of all animals $(A)$, but significance is seen in the group of males when separated by sex (B) * $p=$ $0.01-0.05, * \star \star p=0.0001-0.001$. (C-D) In contrast, when analyzed for GLUT1 protein in isolated capillaries from controls $(n=11)$ and mice treated with $100 \mathrm{mg} / \mathrm{kg}$ VPA $(n=12)$ and $400 \mathrm{mg} / \mathrm{kg}$ VPA $(n=12)$ no significant difference in GLUT1 expression is seen nor when separated by sex (D). One-way ANOVA with Dunnett's multiple comparisons test was used for statistical analysis. Data $(n=11-12)$ are depicted as mean \pm SEM. (E-G) Immunohistochemical detection of GLUT1 (green) in capillaries from cerebral cortex in untreated mice (controls) or mice injected with VPA in concentrations of $100 \mathrm{mg} / \mathrm{kg}$ or $400 \mathrm{mg} / \mathrm{kg}$ allowed to circulate for 24 hours. GLUT1 expression is correlated to that of tomato lectin (red) that labels brain capillary endothelial cells. Treatment with either dose of VPA do not increase the immunolabelling of GLUT1 in brain capillaries. Scale bar: $20 \mu \mathrm{m}$.

A
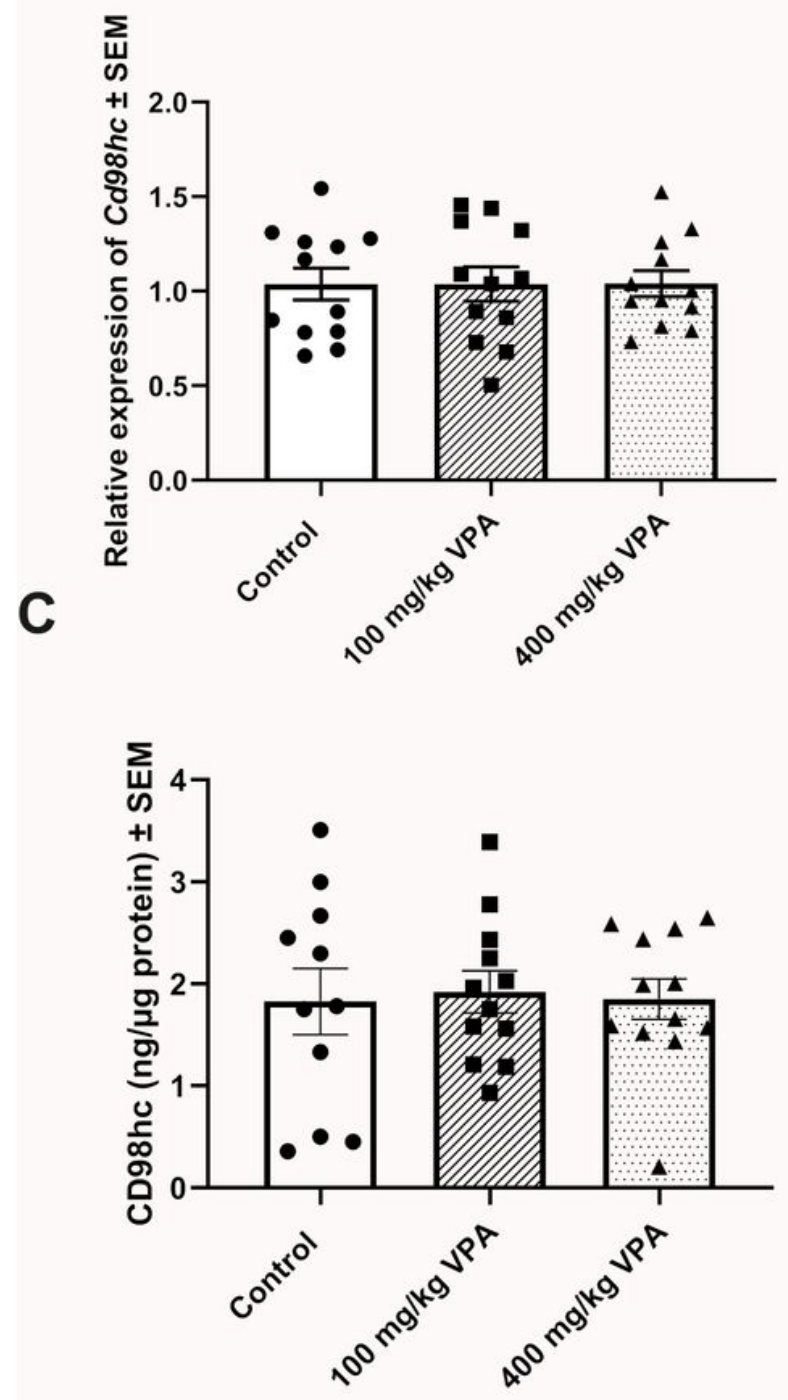

B

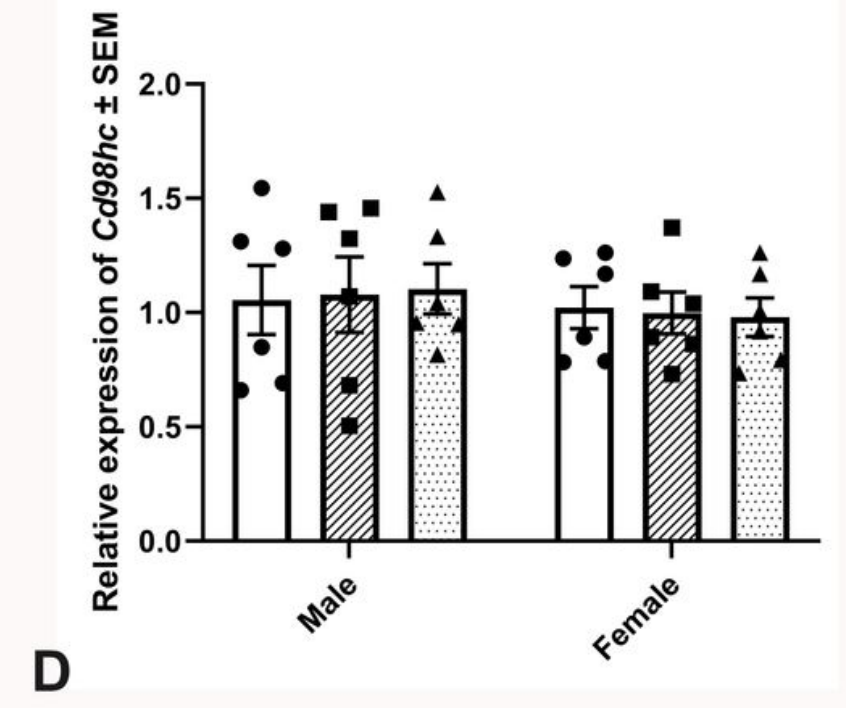

Figure 4 
Expression of CD98hc in brain capillaries after valproic acid (VPA) treatment. (A-B) Cd98hc mRNA expression in capillary depleted brain extracts from mice treated with PBS $(n=12), 100 \mathrm{mg} / \mathrm{kg}$ VPA $(n=12)$, or $400 \mathrm{mg} / \mathrm{kg}$ VPA ( $\mathrm{n}=12)$ for 24 hours. (B.) The Cd98hc expression profile separated based on sex (males $n=6$ and females $n=6$ for each treatment group). A change in gene expression is analyzed using one-way ANOVA with Dunnett's multiple comparisons and when investigating the difference in mRNA expression between male and female mice, a two-way ANOVA with the Holm-Sidak multiple comparisons test is used. Data ( $n=6-12)$ are shown mean \pm SEM. No differences are observed in Cd98hcmRNA in the group of all animals (A), nor when separated by sex (B). (C-D) The expression of CD98hc protein in capillaries of mice injected with PBS $(n=12)$ or VPA in concentrations of $100 \mathrm{mg} / \mathrm{kg}(\mathrm{n}=12)$ or $400 \mathrm{mg} / \mathrm{kg}$ $(n=12)$ allowed to circulate for 24 hours. One-way ANOVA with Dunnett's multiple comparisons test was used for statistical analysis. Data $(n=12)$ are depicted as mean \pm SEM. The VPA treatment does not lead to significant changes in the expression of CD98hc.
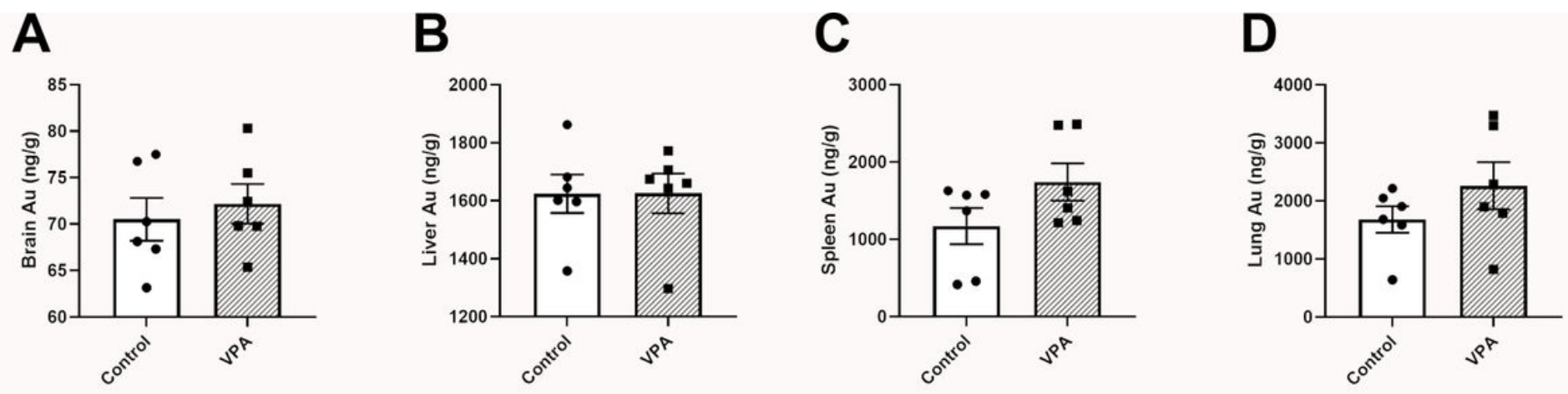

Figure 5

Uptake of gold-labeled TrR1 antibodies. Uptake of Ri7 antibody-conjugated gold $1 \mathrm{~nm}$ nanoparticles in brain, liver, spleen, and lung of untreated and VPA treated mice. Mice were injected with PBS (control) or injected i.p. with $100 \mathrm{mg} / \mathrm{kg}$ VPA and allowed to circulate for 24 hours. Afterwards, the mice were injected with Ri7 antibody-conjugated gold $1 \mathrm{~nm}$ nanoparticles. The uptake of Ri7 antibody-conjugated gold nanoparticles, determined based on the content of gold in the isolated capillaries and brain fraction using ICP-MS, is similar in capillaries of the brain (A), and hepatocytes of the liver (B) in control and VPA injected mice. The uptake in spleen (C) and lung (D) seems to increase slightly, but the difference is not significant. Statistical difference between control and VPA treated animals is analyzed with unpaired ttest, and each point represents data from a single mouse $(n=6)$, and the data are depicted as mean \pm SEM.

\section{Supplementary Files}

This is a list of supplementary files associated with this preprint. Click to download.

- SupplS1.jpeg

- SuppIS2.jpg 